\title{
Some Plants Are More Equal Than Others or Not?
}

\author{
Y. Han Lau (Corresponding author) \\ Botany Department, University of Hawai i \\ 3190 Maile Way, Room 101, Honolulu, HI 96822, U.S.A.
}

Tel: 1-808-956-0936 E-mail: yeong@hawaii.edu

\begin{abstract}
The relationship between Paiwan and their food plants is examined in terms of the functional roles of food processing technologies and traditional ceremonies on the sustainability of Paiwan food plants. A value-added food plant model is developed to predictably understand the persistence of these food plants using ethnobotanical data collected from six Paiwan villages in Taiwan. Three specific case studies of Paiwan food plants are presented as examples of possible outcomes of traditional food plants within the culture in the context of changing cultural and social environments. These case studies demonstrate the potential of food plants to persist in a culture based on traditional practices. The persistence of traditional practices is, in turn, dependent on finding new cultural meanings and economic means to create an environment that is conducive to their continuous existence. Lastly, an understanding of how value is accorded to food plants will allow better decision-making on the conservation of traditional food plants and associated knowledge.
\end{abstract}

Keywords: Paiwan ethnobotany, Traditional food plants, Traditional practices

\section{Introduction}

"All animals are equal but some animals are more equal than others." - George Orwell, Animal Farm

Plants have sustained humans and their economic activities for as long as humans are present on this planet Earth. Long before fire was discovered, plant materials were gathered by humans for food (Shuji 2002) as well as medicines (Johns 1990). Among the many plant materials gathered, starch became the main calorie source from plants (Hotta 2002). Plant families such as the Solanaceae (potatoes), Dioscoreaceae (yams), and Araceae (taros) have starch-storing tubers and corms. Starch from seeds is obtained from plant families such as Poaceae (grasses), Polygonaceace (buckwheats), Chenopodiaceae (quinoas) and Amaranthaceae (amaranths). Do these starch-providing food plants then have the same value within a culture? I seek to answer this question by studying the relationships between Paiwan and their traditional food plants by addressing the null hypothesis that Paiwan traditional food plants have the same values in ways that they are utilized. Specifically, the following food plants Colocasia esculenta (L.) Schott, Setaria italica (L.) P. Beauv. and Chenopodium sp. LYH 115 are investigated in the context of a value-added food plant model.

\subsection{The Paiwan}

The Paiwan is one of the indigenous peoples living in Taiwan. There are about 68,000 Paiwan currently living in Pingtung and Taitung County with many having migrated to cities in the past ten years (Sun 2003). In between Pingtung County and Taitung County is Mount Dawu which is believed by many Paiwan to be their point of origin (Tian 2002). The Paiwan are an ambilineal society headed by a noble chief whose position was inherited (Chiu 1979). Traditionally, the residence of the noble chief is the center of events related to tribal politics, war, religion, and annual celebrations. Each Paiwan tribe is an independent and autonomous unit (Tung 2003). There are basically two classes in their societal organizational structure, namely, the mamazangilan (aristocrats) and the adidan (commoners). In the past, only the mamazangilan had the right to own lands. Commoners, on the other hand, would work on the lands of the aristocrats.

Traditionally, the Paiwan were mountain dwellers. Many of the traditional villages were scattered in the mountains around Pingtung and Taitung Counties. Flat stone slabs were used in the construction of houses in these villages. The Paiwan lived in close proximity to the forests which served as their natural food reserve. Farming and hunting were basically their traditional way of life. Since the Paiwan were living in the mountains, many of their farmlands were established along the slopes of the mountains. In 1895, the Paiwan were systematically moved from their traditional villages in the mountains to the lowlands or areas at the foot of the mountains when the Japanese occupied Taiwan (Tung 2003). As a result, many Paiwan were relocated from their traditional homes in the mountains to a whole new environment in the lowlands.

\section{Methods}

An ethnobotanical research was conducted in six Paiwan villages in Pingtung County in 2004 (Figure 1). All villages 
were in Laiyi, Pingtung County except for Pinghe Village which was located in Taiwu, Pingtung County. Purposive and snowball sampling methods were used to identify 85 informants. Interviews were conducted after informed consent was obtained in Mandarin. Data from free listing of important food plants $(n=84)$ was used to construct an interview guide and used for ethnographic interviews about specific processing techniques of food plants, the use of food plants in ceremonies and rituals, and specific food plant characteristic. Participant observation was conducted to examine daily use of food plants. Herbarium vouchers of traditional Paiwan food plants were collected and deposited in National Pingtung University of Science and Technology Herbarium (PPI, Neipu Township, Pingtung County). Lastly, a value-added food plant model was developed using ethnobotanical data collected from these six Paiwan villages.

\section{Results and Discussion}

\subsection{Value added to Food Plants through Processing, and Incorporation in Ritual Activities}

A culture's food plant use pattern is not static, and the cultural value of a food plant is dependent on the benefits derived from it. Different indigenous peoples choose and use plants differently. Their selection and utilization processes become part of their culture (Prance 2005). They add value to their food plants using various processing technologies. In view of this changing value of food plants with technologies and time, a general model illustrating the relationship between increasing value of food plants and increasing investment of time in processing and using them is developed to predictably understand the persistence of food plants in a culture.

Figure 2 shows the general progression of plants into food and subsequent incorporation into rituals. The Y-axis represents value while the $\mathrm{X}$-axis represents time. Starting at the bottom left of the graph, as a plant undergoes the processing step and is made into food, its value increases. In addition, its value will further increase if the plant or the food made from it is used in rituals or ceremonies. This simplified model depicts the added-value of traditional food plants and related technologies in relation to cultural values. It demonstrates the potential of food plants to persist in a culture based on food and ritual uses. Unprocessed plants have lower values than when they have been processed into food. Consequently, plants with high values will persist and vice versa. Here I present three specific case studies of Paiwan food plants to highlight the status of these traditional Paiwan food plants in Paiwan culture across time.

\subsection{Case Study 1: Taro}

C. esculenta or taro is an ancient crop with a long history (Martin 2004). As with many other cultures in the Pacific, vasa (taro) is the main staple for the Paiwan. The Paiwan refer to the main taro corm as buku (mother corm) and use it for the propagation of new taro. Only the butil, which is the young corm or sucker that branches out from the mother corm is consumed.

One very common method of cooking taro is to steam it. In addition, the Paiwan also dehydrate and roast taro to make aradj (roasted taro). The whole process of making aradj is very laborious. It is not uncommon for one roasting session to last continuously for several days depending on the amount of taro. In addition, taro is roasted on specially built stone ovens called leut (stone oven for roasting taro). Experience and skills are needed to make roasted taro using the traditional method. Currently, few Paiwan are making aradj for a living now.

In Figure 3, the value of taro increases as it is being processed and made into food. Due to the relatively complex way of roasting taro, aradj has a higher value than steamed taro. The knowledge associated with making aradj is an important aspect of Paiwan culture. Unlike steamed taro which can be easily cooked by anyone, aradj requires a set of unique cooking methods and facility. The practical knowledge on making aradj is currently retained by only a few older individuals per village who still make this traditional food for a living, and hence, keep this traditional alive. While this is encouraging, the reality is that the Paiwan generally harvest taro at the end of the year. Anyone wishing to roast taro for a living can only do it for a relatively short period of time at the beginning of the year after the taro harvest period. The cyclic production and demand for this traditional food may not be attractive enough to encourage more Paiwan to perpetuate this traditional skill. Moreover, younger Paiwan who already have work commitments in the cities find it difficult to devote time to learn this traditional process. As fewer individuals get involved in making aradj, this traditional food and its corresponding cooking method will inevitably fall into the danger of becoming a piece of static cultural information. The value of taro in the culture may decrease in the future if no one decides to make aradj anymore. Nevertheless, for the time being, taro will continue to persist as a traditional food plant because steamed taro is still regularly consumed.

\subsection{Case Study 2: Millet}

$S$. italic or millet, another traditional staple of the Paiwan, is sown some time in May just before the rain comes by broadcasting the seeds in pure stands. The spikes of the millets are cut off during harvest in August. The Paiwan will bundle the millet and let them dry under the sun. The millets are husked only when they are being used for food.

In Figure 4, the value of vaqu (millet) increases as it is being processed and made into cinavu which is a traditional Paiwan food. Cinavu is still commonly prepared by many Paiwan and is often eaten during festive occasions. Hence, 
the knowledge base is not restricted to only a few individuals. The importance of millet in Paiwan culture is further demonstrated by the fact that the Paiwan celebrate the final harvest of millet by holding masalut (post-harvest celebration) annually. By doing this, the value of millet further increases.

Millet is a traditional food plant that is just persisting in the culture. Being one of the chief ingredients of cinavu, the availability of millet is important for the perpetuation of this traditional food. Unfortunately, millet farming is on the decline as many Paiwan farmers have given up on millet farming. The implication is that the supply of millet will decline and this, in turn, affects the availability of cinavu. I interviewed Paiwan farmers regarding the reason for the decline in millet farming. The answer that I consistently got was that millet farming was a very tiring job. Moreover, birds were constantly feeding on the seeds of millet which made the work of farming millet even less appealing. Many farmers simply gave up on farming millet as they found that they would be economically better off to simply fallow their land since Taiwan's Council of Agriculture were actually compensating farmers financially to do just that. If this trend continues, the annual post-harvest celebration may eventually lose its meaning when there is no more millet left to harvest.

\subsection{Case Study 3: Djulis}

Djulis (Chenopodium sp.) was a traditional food plant that seemed to be limited to the Paiwan living in north-eastern part of Pingtung County. I did not find anyone growing djulis in my visits to other Paiwan villages outside the north-eastern part of the county. Hence, the subsequent discussion also includes interviews with eight Paiwan living in Majia and Taiwau Townships that are in the north-eastern part of Pingung County. These eight informants had planted djulis and were able to describe the traditional use of djulis as food.

Djulis was traditionally grown for its seeds which were consumed in the same way as other cereal grains. To harvest the plant, the infructescence were first sorted out, cut and laid out to dry under the sun. After drying, the infructescence were threshed with wooden mortar and pestle. Subsequently, the seeds were separated from the "husks" with a sieve and washed with water several times to remove saponins. This was a crucial processing step as consuming unwashed seeds would lead to some form of intoxication. Incidentally, another traditional use of the djulis was as a fermenting agent in the making of vinawa (millet beer). According to custom, vinawa prepared using djulis was only consumed during festive seasons (Hsu 1990).

In Figure 5, the value of djulis increases as it is being processed and used as food and a fermenting agent. Although no longer a current major food crop among the Paiwan and no longer grown as a primary crop plant in farms, djulis is still eaten by some older Paiwan in the villages. However, the use of djulis as a fermenting agent is no longer observed, and specific knowledge regarding this particular traditional use is lacking. Fortunately, a nation-wide effort to promote indigenous cultures (Sun 2003) has resulted in many Paiwan rediscovering djulis as they learn about their cultural past from their elders. To the Paiwan, djulis is reclaiming its status as a plant with a deep cultural value. Some Paiwan are even experimenting with developing modern Paiwan cuisine which includes cinavu made with djulis instead of millet, djulis-flavored desserts, djulis-flavored soups and even djulis-flavored coffee. Hence, djulis can be considered as a food plant that is experiencing a revival due to changing social and cultural landscapes. It is an example of a traditional food plant that is being revived by the Paiwan.

\section{Conclusion}

Taro is still being planted, and the technologies associated with it are still present. This is a traditional food plant that is still persisting within the culture. On the other hand, millet is seldom being planted now even though the technology to make food from it is present, and the annual post-harvest festival is still being celebrated in Paiwan villages. However, the impending scarcity of millet makes this food plant to be just persisting within the culture. Djulis is a food plant that is experiencing a revival but traditional knowledge about the plant is lacking. Nevertheless, new knowledge is being gained as the Paiwan are beginning to experiment with the plant for food.

Figure 6 summarizes the persistence of taro, millet and djulis in Paiwan culture across time. The Ideal Persistence Progression Curve (IPPC) is a hypothetical path that a plant will ideally take as it gets processed and used as food or in rituals. Taro's persistence progression curve will be similar to IPCC as it is still being planted and utilized. Millet's value, as indicated by its persistence progression curve, is falling as the Paiwan have gradually stopped planting it. Djulis is being revived and its persistence progressing curve shows a large plunge before climbing up again.

The persistence of traditional food plants in a culture is influenced by traditional practices that are associated with them. The persistence of these traditional practices is, in turn, dependent on the ever-changing lifestyle of a culture. As traditional practices are losing their relevance in today's lifestyle and no longer being observed, traditional knowledge of associated food plants will also be forgotten. One way to ensure that traditional plant knowledge is not lost is to find alternative meanings for the plants to ensure that the plant values remain high within the culture. This will help plants to persist within a culture, and consequently, the retention of traditional knowledge associated with it.

From the above discussion, Paiwan traditional food plants do not have the same values within a culture. Some plants are 
more equal than others at any one point in time depending on the current needs and lifestyle of the culture in question. In addition, a food plant can have more than one use within a culture. Although not discussed in this paper, I am currently following up on this research to include multiple-use factor of plants in our model from a non-linear perspective which will provide us with a better idea on the persistence path of food plants in a culture.

\section{References}

Chiu, C.-C. (1979). The aborigines of Formosa. Taipei: Center for Public and Business Administration Education National Chengchi University

Hotta, M. (2002). The origins and spread of tuber crops (imo). In Y. Shuji and P. J. Matthews (Eds.), Vegeculture in Eastern Asian and Oceania. Osaka: Japan Center for Area Studies

Hsu, G. M. (1990). An investigation of Paiwan's custom of drinking alcoholic beverages in Gulou. Institute of Ethnology Data Organization Series 1. Taipei: Institute of Ethnology

Johns, T. (1990). With bitter herbs they shall eat it: Chemical ecology and the origins of human diet and medicine. Tuscon: University of Arizona Press

Martin, G.. (2004). Ethnobotany: A methods manual. London: Earthscan Ltd.

Prance, G. (2005). The seeds of time. In G. Prance and M. Nesbitt (Eds.), The cultural history of plants. New York: Routledge

Shuji, Y. (2002). Wild food plants and vegeculture. In Y. Shuji and P. J. Matthews (Eds.), Vegeculture in Eastern Asian and Oceania. Osaka: Japan Center for Area Studies

Sun, T.-C. (2003). The existence and future of indigenous peoples in Taiwan. In C.-N. Chen, (Eds.), Assembly of Austronesian leaders presentation report. Taiwan: Council of Indigenous Peoples, Executive Yuan

Tian, Z. (2002). Indigenous Peoples of Taiwan: The Paiwan. Taipei: Tai Yuan Publishing

Tung, C.-f. (2003). An introduction to Taiwan's Indigenous Peoples and Culture. In C.-N. Chen, (Eds.), Assembly of Austronesian leaders presentation report. Taiwan: Council of Indigenous Peoples, Executive Yuan

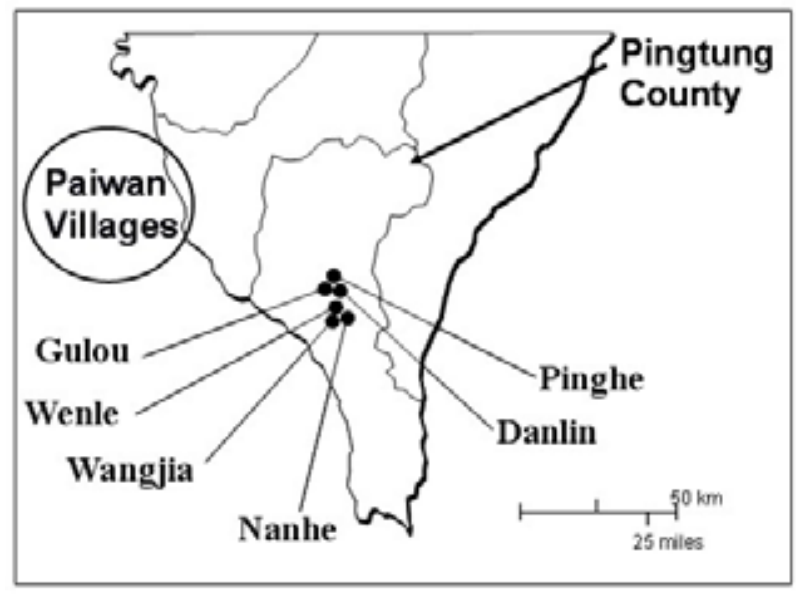

Figure 1. Six Paiwan villages in Pingtung County, Taiwan that were included in this study.

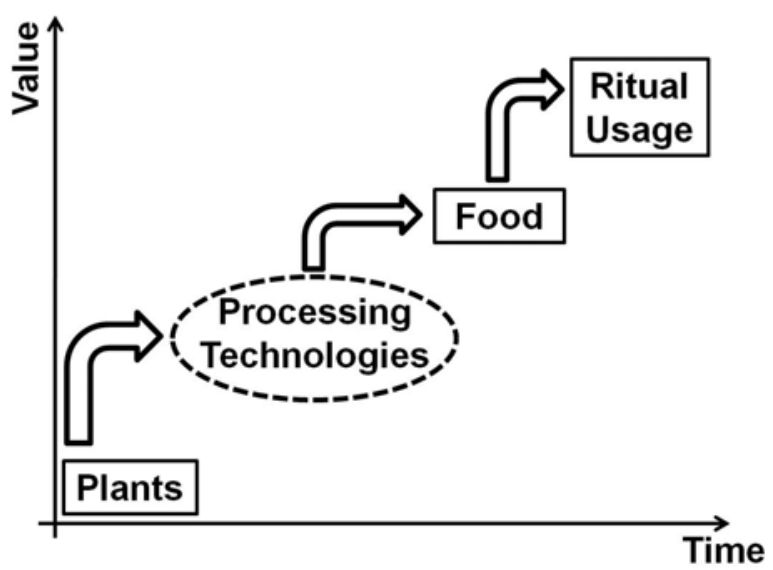

Figure 2. Positive relationship between

1) investment of time and effort and

2) value of the product resulting from this investment. 


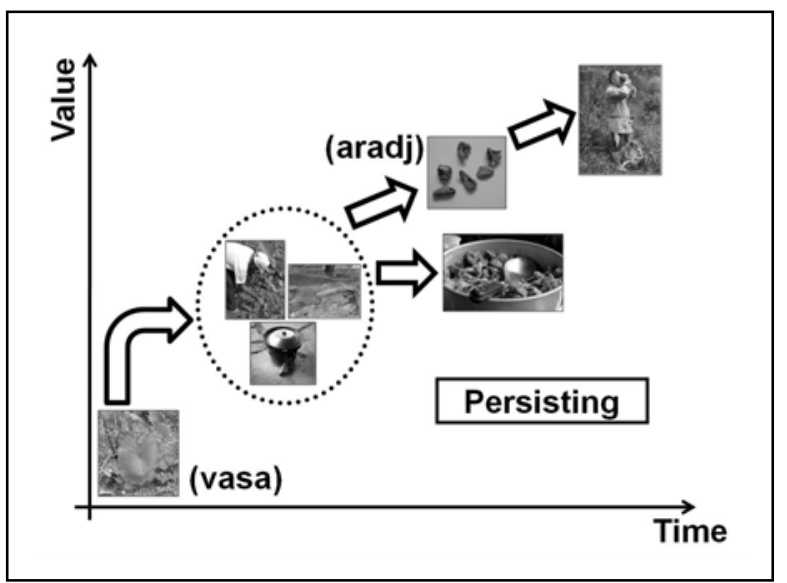

Figure 3. An "added-value of food plants" model illustrating the transformation of taro into food. Aradj, due to its light-weight, is a food favored by hunters.

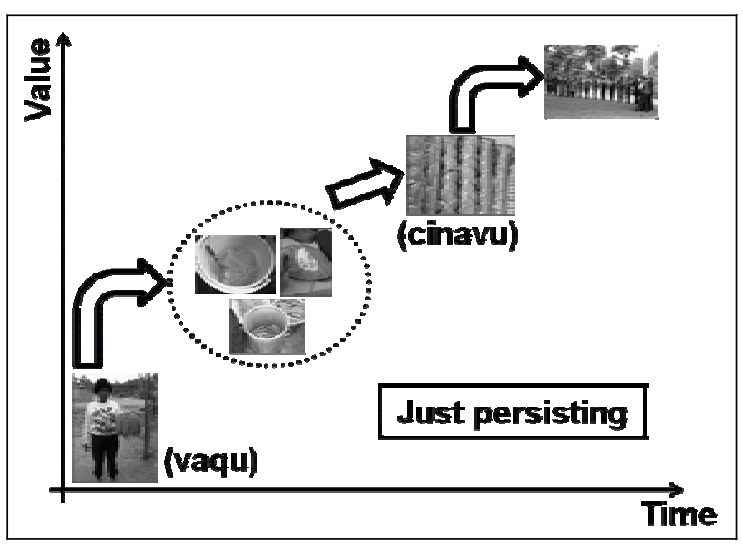

Figure 4. An "added-value of food plants" modelillustrating the transformation of millet into food.

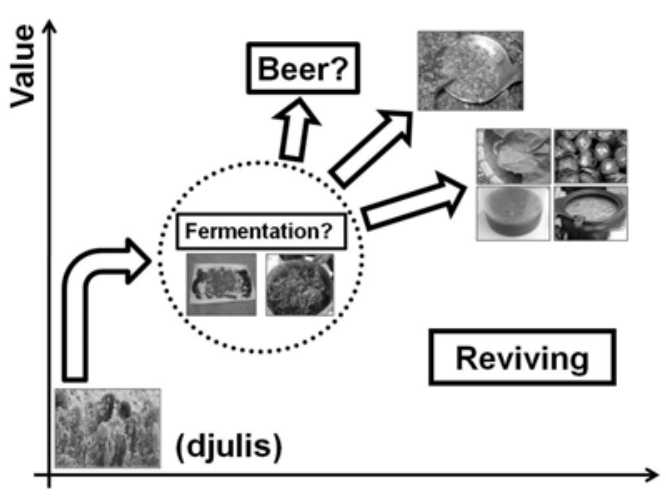

Figure 5. An "added-value of food plants" model illustrating the transformation of djulis into food.

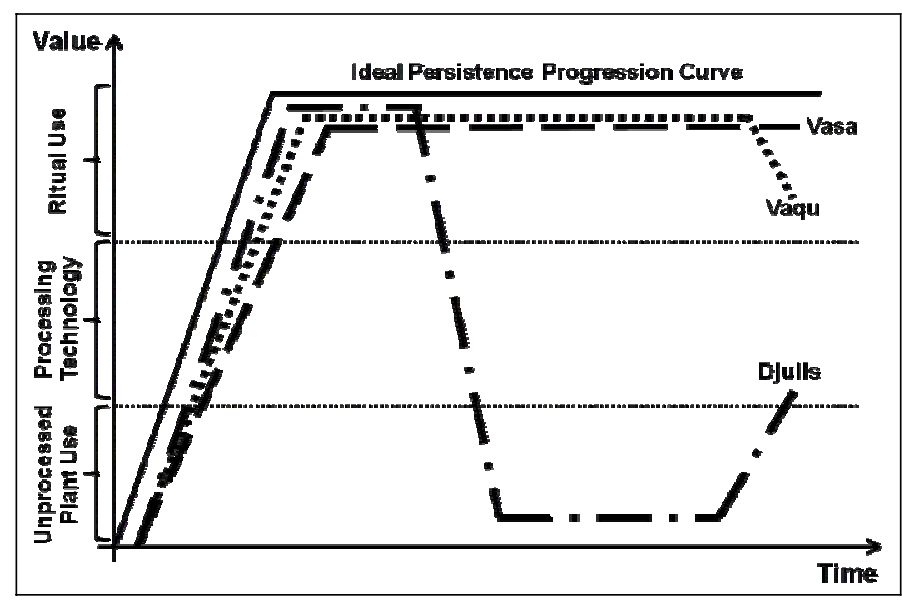

Figure 6. Hypothetical Ideal Persistence

Progression Curve and the Persistence Progression Curves of vasa, vaqu, and djulis. 